\title{
Microstructure characterization of male and female external genitalia of soapberry bug, Leptocoris augur (Hemiptera: Rhopalidae)
}

\author{
Vaishali J. Badwaik ${ }^{1 *}$, Deepak D. Barsagade ${ }^{2}$ \\ ${ }^{1}$ Department of Zoology, Vidyabharti College Seloo, Wardha, India. \\ ${ }^{2}$ Department of Zoology, MJF Educational Campus, RTM Nagpur University, Nagpur, India.
}

\begin{tabular}{l}
\hline ARTICLE INFO \\
\hline Article history: \\
Received on: March 28, 2021 \\
Accepted on: June 25, 2021 \\
Available online: September 01,2021
\end{tabular}

Key words:

External genitalia, host plant,

Leptocoris, sensilla, SEM

\section{INTRODUCTION}

Heteropteran "stink bug" (e.g., Pentatomidae) possess scent glands in their abdominal segments that secrete an unpleasant smelling substance to save themselves from being attacked. On the contrary, the Rhopalid bugs, Leptocoris augur (Fabricius 1781), do not have any scent gland(s) in their abdominal segments, which is a characteristic of the Rhopalidae family [1]. They are plant bugs and belong to the superfamily Coreoidea, which includes 21 genera [2]. The Rhopalid bugs are commonly called scentless plant bugs, as the scent glands are absent. However, this term is misleading and inappropriate (in terms of identifications) because some rhopalids commonly produce redolent compounds [3].

External genitalia and its microstructure play an important role in identifying species; in some instances, it is difficult to identify on the basis of morphology only [4]. Rhopalidae bugs are particularly "plant bugs", as they are always associated with plants [5-7]. Mead and Fasulo [1] and Barsagade and Badwaik [8] reported

*Corresponding Author

Vaishali J. Badwaik, Department of Zoology, Vidyabharti College Seloo, Wardha, India.E-mail: vaishalijbadwaik@gmail.com on Sapindaceae as primary hosts plants for Leptocoris and its closely related genus Jadera. In addition, we also noted that the bug, Leptocoris, colonizes on other secondary host plants like, Butea monosperma (Palas), Euphorbia geniculata (Dudhani), Ampelocissus latifoloa (Dokela), Ceiba pentandra (Savar), Psidium guajava (Guava), Bougainvillea, and Lablab sp. (Fig. 1a-f). Scentless plant bugs, L. augur and Liorhyssus hyalinus, are economically important, as they can attack certain vegetable crops like cucumber, pumpkin, and cabbage, which leads to economic loss $[9,10]$. To avoid such damage, pest population (e.g., plant bugs) needs to be checked. In addition, to study the behavioral aspect and alternative pest control strategies (e.g., pheromone traps), the sensory microstructure has been investigated during the course of the present study.

The external genitalia of plant bugs have been characterized for taxonomic applications, while the external female genitalia of the Triatominae subfamily have been rarely characterized for taxonomy [11-13]. Scanning electron microscopy (SEM) study of the external genitalia of some insect species, e.g., Rhodnius prolixus, Rhodnius colombiensis, Panstrongylus herreri, and Panstrongylus megistus, suggests the role of its genitalia morphology in taxonomical study [14]. 
Many workers have dealt with the morphological studies of Rhopalidae family for the life cycle and host plant studies [9,1518]. However, the present study provides a detailed description of both male and female genitalia of soapberry bug, L. augur, based on scanning electron microscopic studies for the first time. The study revealed the presence of different types of the sensillae present on genitalia, and their possible role and structure of the ovipositor have been discussed. Examination of external male and female genitalia of L. augur suggests that it may be helpful for the taxonomical studies of the Rhopalidae family. Moreover, it would be a preliminary report to study these bugs more in details to study behavior and to address the pest control strategies of the soapberry plantations.

\section{MATERIALS AND METHODS}

\subsection{Insect Resources, Study Site, and Field Observation}

The soapberry bug L. augur is a major pest of the "Reetha" plant, Sapindus saponaria L. (Family: Sapindaceae). The bugs and host plant studies were conducted in and around the RTM University Campus, Amravati Road, Nagpur, Maharashtra, India (21 $1^{\circ} 14^{\prime} \mathrm{N}$, $\left.79^{\circ} 03^{\prime} \mathrm{E}\right)$, located in the Deccan peninsular plateau.

The study site was dominated by the host plant, $S$. saponaria (Sapindaceae), with enormous bugs population, from where the sample were collected for the present study (Fig. 1, a-f). The collected specimens, i.e., nymphs and adult bugs, were brought to the laboratory and colonies were maintained during the course of the present study. During the period of study, the environmental parameters were recorded. The average annual temperature was $27^{\circ} \mathrm{C}$, the average annual humidity was $50 \%$, and the average annual precipitation was $\sim 1,100 \mathrm{~mm}$. Leptocoris bugs were collected from the month of October to January, from the year 2012 to 2014 . The average temperature range was between 17.4 $\pm 0.4^{\circ} \mathrm{C}$ and $21.2 \pm 0.3^{\circ} \mathrm{C}$, and the relative humidity was $77.2 \pm$ $0.6 \%$, and the mean rainfall recorded was $39 \pm 0.5 \mathrm{~mm}$.

\subsection{Light Microscopy}

For the light microscopic study, the external genitalia with the last abdominal segments were dissected out under the stereoscopic binocular microscope (Carl Zeiss Stemi DV4). The freshly dissected genitalia and ovipositor assembly were treated with $10 \% \mathrm{KOH}$ (hot) for 15-20 minutes. The material was washed in acetone to remove the content of $\mathrm{KOH}$, then dehydrated in ascending grades of alcohol and cleared in xylene, and mounted in dibutylphthalate polystyrene xylene (DPX).

\subsection{Scanning Electron Microscopy (SEM)}

For scanning electron microscopy, adult male and female external genitalia were dissected in saline water. The dissected parts were washed thoroughly and dehydrated in graded series of alcohol, for 5-10 minutes in each grade. The material was cleared in xylene, air-dried in room temperature, and mounted on SEM metallic stubs under the stereoscopic binocular microscope (Carl Zeiss Stemi DV4). The materials were coated with the thin layer of platinum in vacuum evaporator, evaced, and scanned under the JEOL JSM6380A SEM. Observations were carried out at the Instrumentation Centre, Vishvesvaraya National Institute of Technology (VNIT) Nagpur, India.

\subsection{Statistical Analysis}

Morphological measurements of the ovipositor, adeagues, valvifers, and sensilla present on the external genitalia of the male and female bugs were calculated. The software application Digimizer Version 4.6.1 MedCalc was used for the image analysis and some calculations. The Microsoft Excel software was used to calculate an arithmetic means and standard errors.
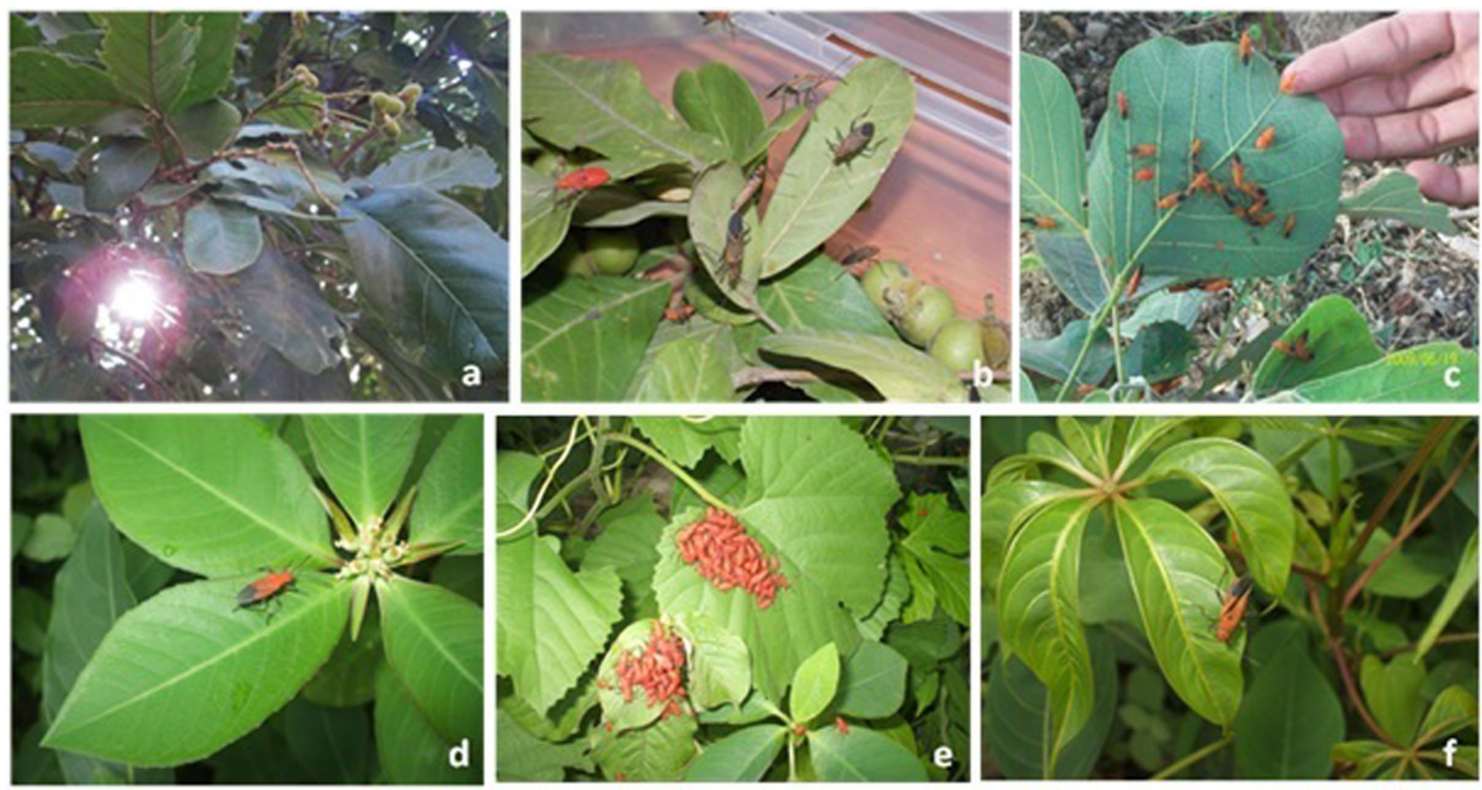

Figure 1 . Host plants. (a) S. saponaria, (b) S. saponaria (rearing box), (c) B. monosperma (Palas), (d) E. geniculata (Dudhani), (e) A. latifoloa (Dokela), and (f) C. pentandra (Savar). 


\section{RESULTS}

\subsection{Leptocoris augur}

The bugs were collected from host plants and the surrounding vegetation, and identification was made by Dr. V. V. Ramamurthy, Taxonomist Indian Agricultural Research Institute, New Delhi. The specimen was identified as L. augur (Fabricius, 1781). There was no sexual dimorphism. Male and female were approximately similar in appearance, except females were longer than males (Fig. $2 \mathrm{a}-\mathrm{c})$. The head and thorax were dull red with a bright red colored abdomen and the wings were fully developed and extend up to the last abdominal segment. The adult male is about $9.14 \pm 0.026 \mathrm{~mm}$ and the female is about $14.00 \pm 0.06 \mathrm{~mm}$.

\subsection{Morphology of Female External Genitalia and Ovipositor}

The female external genitalia of $L$. augur are present on the VIIIth and IXth segments. The VIIth segment is the last visible segment which is deeply concave posteriorly. The IXth and Xth segments are significantly reduced. The first pair of valvifers is present on the Xth segment, while the second pair of valvifers is present on the IXth segment. The VIIIth segment is narrow dorsally and has two lateral tergites, which are covered with thick bristles. The $\mathrm{Xth}$ segment is narrow and encloses the IXth segment almost completely, which surrounds the anus. The first and second pair of valvifer covered the shaft of the ovipositor externally. The ovipositor arises from the VIIIth segment and extends up to IXth segment, and the length of ovipositor is $256 \pm 0.55 \mu \mathrm{m}$. The ovipositor is without sensilla and having smooth surface. Female use their ovipositors to search for suitable sites to lay their eggs. They lay eggs on abaxial surface of leaves of the host plant.

\subsubsection{Distribution of sensilla}

The microtrichia (Mt) are present surrounding to the surface of the ovipositor. Mt are mechanoreceptors helpful to select the leaves surface of host plant for egg-laying. Two pairs of valvifers bear distinct sensillum. The first pair of valvifers (V1) bears a very thick setae and a number of long sensilla trichoidea (ST). The second pair of valvifers (V2) bears a ST, and based on their length, there are two types, ST-I and ST-II, sensilla trichoidea curvata (STC) and Mt. Setae (S) are very thick mechanoreceptor and specific distinct ridges seen on the surface. ST are the long hair-like simple and flexible mechanoreceptors arising from the socket, broad at the base and tapering toward the apex. STC are broad at the base and curved at the apex (Fig. $3 \mathrm{a}-\mathrm{i}$ and Table 1).

\subsection{Morphology of Male External Genitalia}

The male external genitalia of $L$. augur are present on the IXth segment. The external genitalia comprises a pair of aedeagus, a pair of clasper, a pair of paramere, and a pair of phallobase (PB). The pair of conical claspers and a pair of rounded clasper are present on the Xth segment. The male copulatory organ or aedeagus base is hinged on a tubular elongated basal plate and PB. At the anterior end of the genital area, lateral to the aedeagus and above the basal part of $\mathrm{PB}$, a pair of triangular-shaped ventral processes, the parameres (PM), are present (Fig. $4 \mathrm{a}-\mathrm{i}$ ).

\subsubsection{Distribution of sensilla}

The long ST are distributed on the dorsal surface of the aedeagus. ST are long hair-like sensilla, and based on their length, there are two types of sensilla, named as ST-I and ST-II. The ventral terminal surface of aedeagus bears sensilla basiconica (SB) and sensilla coeloconica (SC). SB are short with a broad base, and $\mathrm{SC}$ are small with a terminal pore. PM and PB was with smooth surface without sensilla. Claspers have two types of sensilla, ST and STC (Fig. 4a-i; and Table 1).

\section{DISCUSSION}

The external genitalia are an important tool for taxonomy and are very useful for identification at the genus and species level. The morphological variation observed in external genitalia might be the key for phylogeny [14,19-21]. In the present study, the surface ultrastructure of male and female external genitalia of soapberry bug, L. augur, shows the presence of two pairs of valvifers in female bugs and presence of conical claspers, elongated PB, triangular paramers in male bugs might be a specific morphological key for the Rhopalidae family.

Surface ultrastructural study of the female external genitalia of L. augur reveals the presence of two pairs of valvifers enclosing the ovipositor. The ST, STC, Mt, and setae present on pair of valvifers were confirmed during the present SEM study. The presence of such mechano- and chemoreceptors help in host location behaviors, that examines the suitable sites or surface of the host plant for their egg-layings. Similarly, the presence of such mechano- and chemoreceptors on the ovipositor valve also help to regulate the egg-laying mechanism on other host species (during parasitization), and their possible role in oviposition behavior are well documented [22,23]. An important role of chemoreceptors in host recognition is also suggested by Anderson and Hallberg [23].
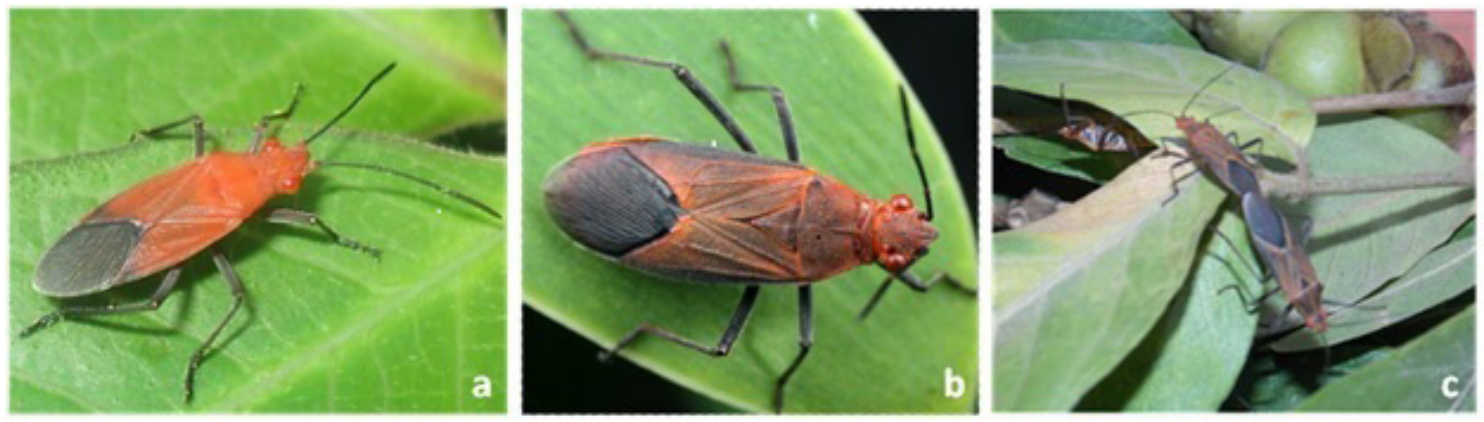

Figure 2. Adult bug L. augur. (a) Male. (b) Female. (c) Mating. 
Badwaik and Barsagade: Microstructure characterization of male and female external genitalia of soapberry bug, Leptocoris augur (Hemiptera: Rhopalidae) 2021;9(05):26-32

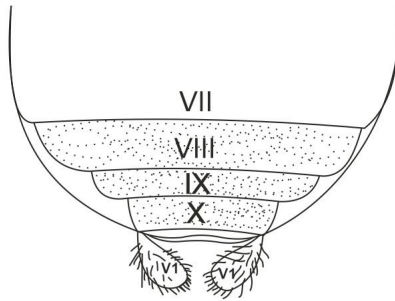

(a)
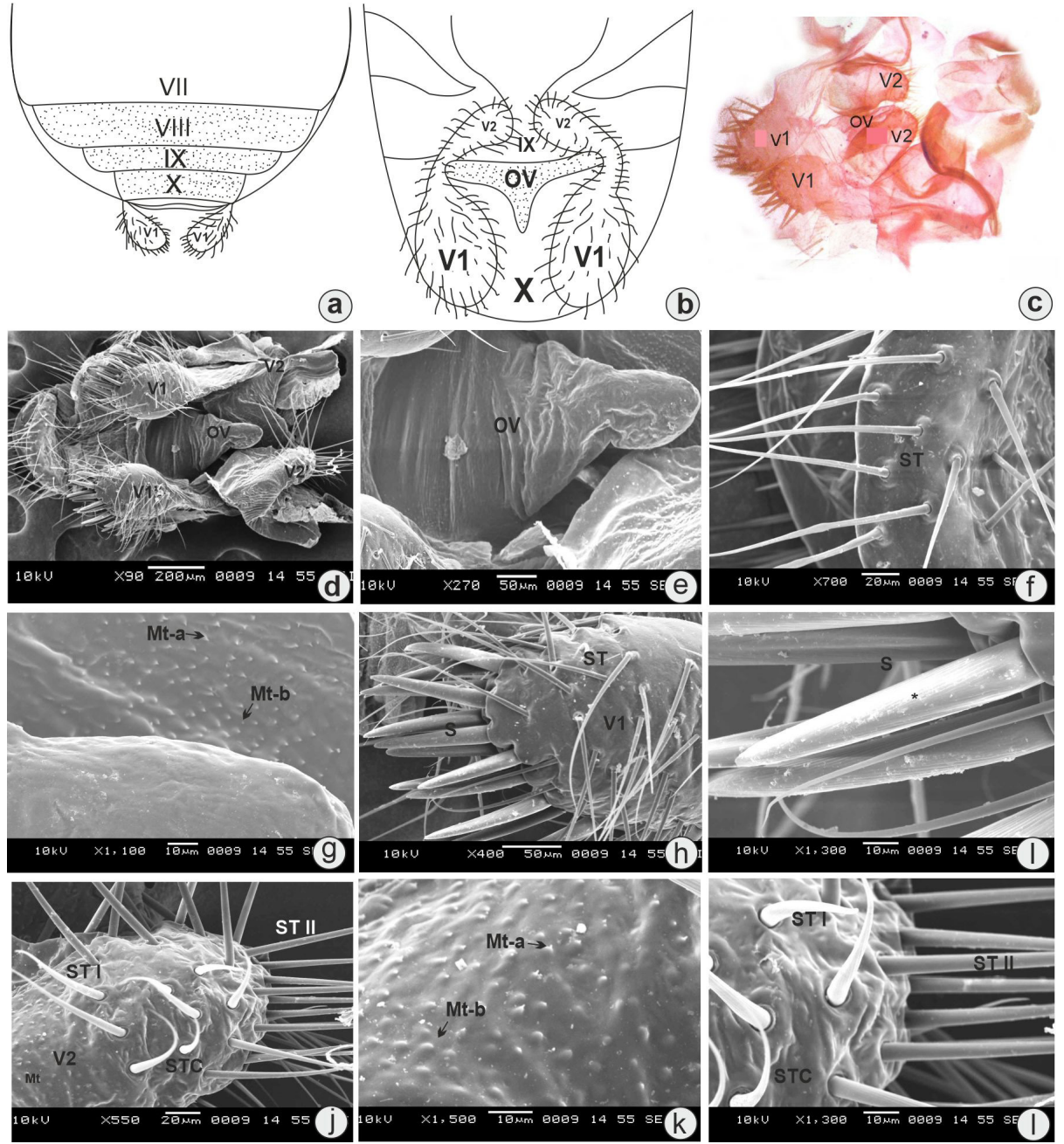

Figure 3. (a) Dorsal view of female external genitalia (diagrammatic). (b) Ventral view of female external genitalia (diagrammatic). (c) Light microphotograph showing valvifer (V) arrangement and ovipositor. (d) SEM view of female external genitalia showing arrangement of valvifer, (V1) and (V2), with ovipositor. (e) SEM photomicrograph magnified view of ovipositor (OV) with smooth surface. (f) ST present on ovipositor stylets. (g) Microtrichia (Mt-a) and (Mt-b) on the surrounding surface of the ovipositor. (h) ST and setae (S) present on first pair of valvifers (V1). (i) Magnified view of setae showing ridges (*) on the surface. (j) ST-I, ST-II, and STC present on the second pair of valvifers (V2). (k) Microtrichia (Mt-a) and (Mt-b) on the surface of ovipositor stylets. (i) Magnified view of ST-I and STC.

Table 1. Morphological observations of sensilla present on external genitalia of adult $L$. augur $(n=10)$.

\begin{tabular}{clccc} 
& & Types of sensilla & Length $(\mathbf{m m})$ & Width $(\mathbf{m m})$ \\
Female & Valvifer I & ST & $132 \pm 2.2$ & $3.7 \pm 1.6$ \\
& & Setae (S) & $77.9 \pm 2.1$ & $19.4 \pm 1.9$ \\
& Valvifer II & ST-I & $149 \pm 3.2$ & $2.1 \pm 1.1$ \\
& & ST-II & $47.9 \pm 2.2$ & $3.1 \pm 1.8$ \\
& Mt & & \\
& & STC & $37.2 \pm 1.2$ & $3.5 \pm 1.2$ \\
& Ovipositor & - & - & - \\
Male & Inner surface & Mt-a & $24.4 \pm 4.1$ & $1.29 \pm 0.6$ \\
& Claspers & Mt-b & $4.58 \pm 2.2$ & $0.95 \pm 0.3$ \\
& Aedeagus & ST & $120 \pm 0.1$ & $1.2 \pm 0.2$ \\
& Paramers & ST & $119 \pm 1.5$ & - \\
\hline & Phallobase & SC-a & - & \\
\hline
\end{tabular}



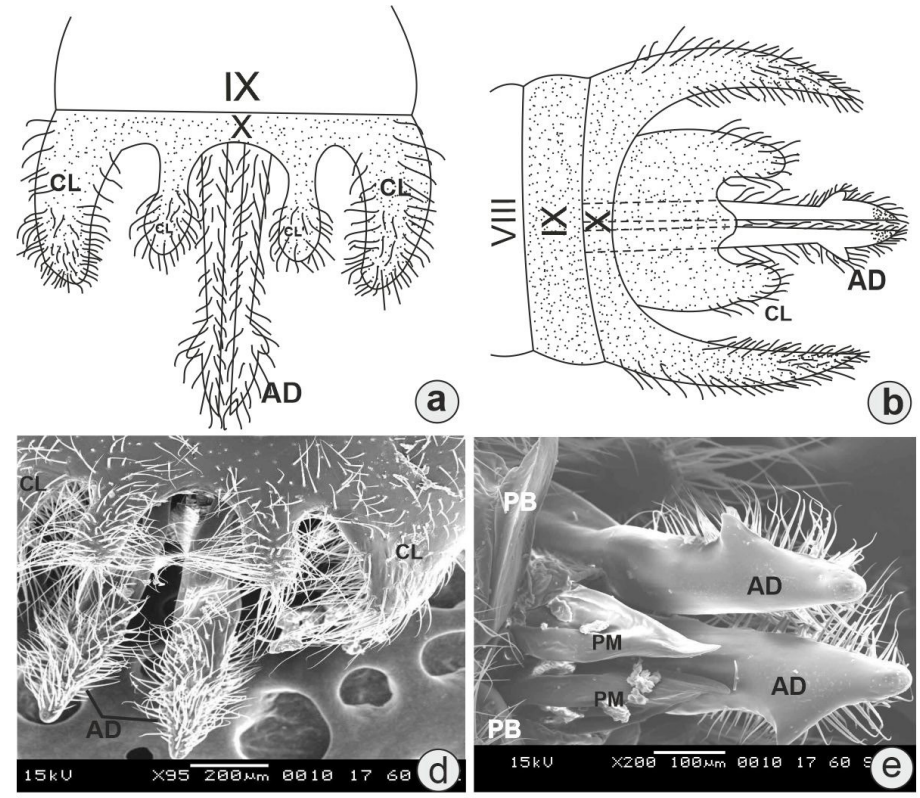

(b)
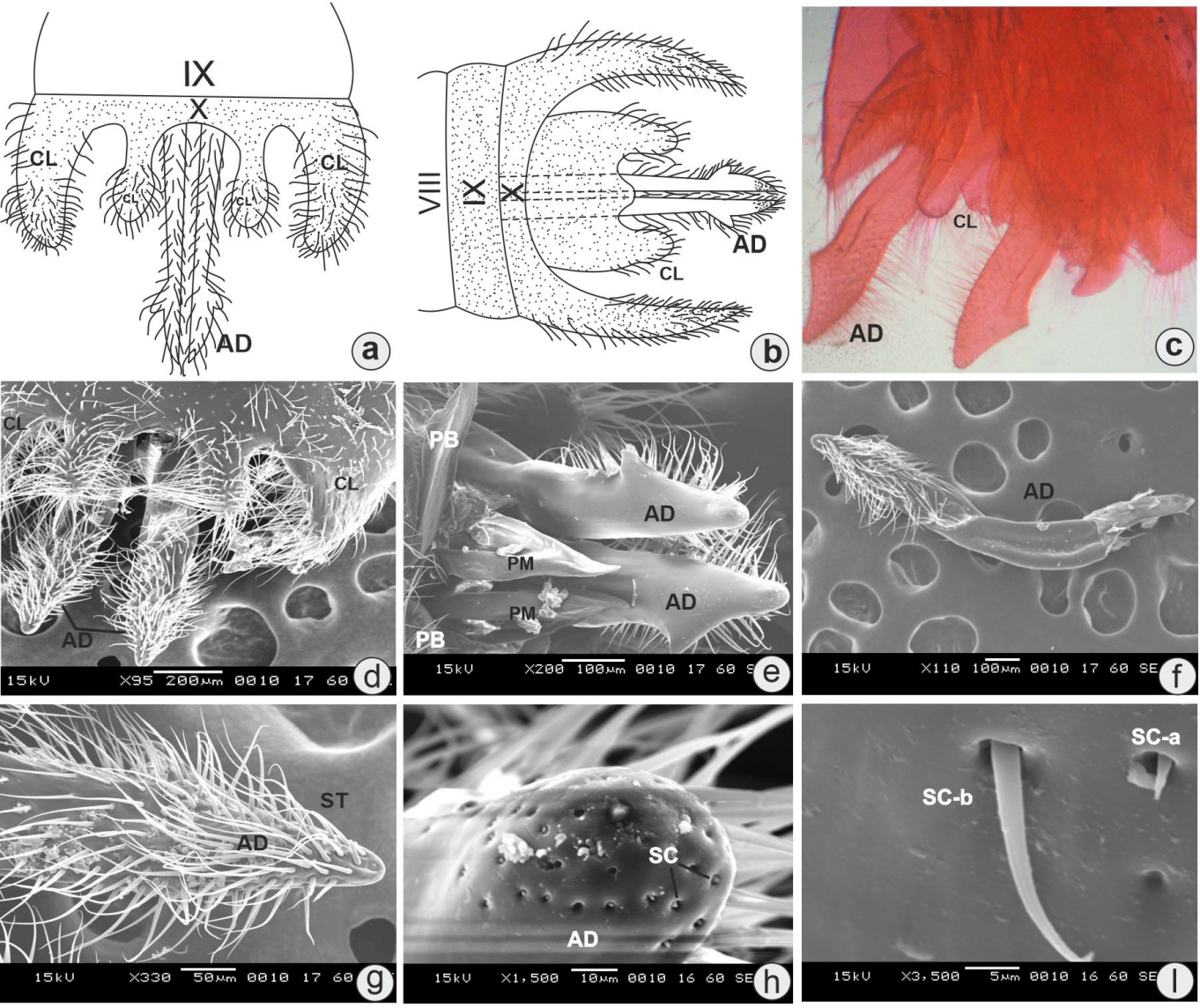

Figure 4. (a) Dorsal view of male external genitalia (diagrammatic). (b) Ventral view of male external genitalia (diagrammatic). (c) Light microphotograph showing aedeagus and clasper. (d) SEM view of male external genitalia. (e) SEM photomicrograph magnified view of aedaagus (AD), paramers (PM), and PB. (f) SEM photomicrograph magnified view of AD showing its complete length. (g) ST on surface of AD. (h) SC on the tip of AD. (i) Magnified view of SC-a and SC-b.

Similarly, sensillae present on the valvifers helps to identify the site of host plants for egg-laying and are reported in other species of the insect [23-25].

The female external genitalia of $L$. augur present on the VIIIth and IXth segments. A similar type of morphological structure is present in other insects as well [26]. With this microstructure endow, Mt are uniformly distributed on the ovipositor stylets. Many researchers have highlighted the presence of Mt on insect external genitalia with their possible role. Sensillae present on external genitalia have important roles during mating events and in oviposition behavior [27-29]. The intraspecific differences were not examined in the external genitalia of 14 Rhodnius species [30].

The male external genitalia in many species of Hemiptera are used for taxonomic studies and species determination [31-34]. In the present study, the peculiar structure of the male external genitalia of L. augur is the characteristic feature of the Rhopalidae family. In the Rhopalidae family, a pair of conical and rounded claspers with triangular-shaped PM are present. The male external genitalia of $L$. augur present on the IXth segment. A similar structure of external genitalia was described by earlier workers in Heteropteran species $[26,35,36]$. The well-developed male external genitalia consist of the phallus as basal and aedeagus as apical part. In most of the Hemipteran species, the aedeagus is the largest structure of the male genitalia [37].

The present study shows that the male copulatory organ or aedeagus base is hinged on the basal plate, PB (phallus). Generaand species-wise, the aedeagus shape is variable [38]. The shape of the aedeagus in $L$. augur is elongated with a triangular tip during the present study. In Hemiptera, above the phallus and at the end of genital segments, cone-shaped ventral PM are present. These structures are similar to the claspers belonging to the other families/orders $[39,40]$. The paired PM lying lateral to the aedeagus above the phallus are conical in shape, and the function of these PM is as grasping apparatus during copulation [41-44].

The present SEM study reveals that the aedeagus was covered with ST, STC, and SC. The presence of SC on the genital area helps in courtship behavior of the bug, and it might have the function of thermoreception or hygroreception [45]. The male genitalia have been repeatedly used as important taxonomic characteristics and the microstructures present on the surface have important role in mating events and copulatory behavior $[11,46]$. 


\section{CONCLUSION}

The examination of male and female external genitalia of L. augur has been characterized by light and scanning electron microscopy studies. This study suggests that these components may be helpful for taxonomical studies of Rhopalidae family. In this study, we have reported the various types of sensillae present on the external genitalia of L. augur, probably involve in the host plant selection and copulatory behavior. The present study may help to explore further research intentions in detail courtship behavior.

\section{ACKNOWLEDGMENTS}

The authors are thankful to the Department of Zoology, MJF Educational Campus, RTM Nagpur University, Nagpur, for providing the lab facility. They also thank the Director of VNIT, Nagpur, for the SEM studies, and Dr. B. Ghaisas, Principal, Vidyabharti College Seloo, Wardha, for constant encouragement.

\section{AUTHORS' CONTRIBUTION}

The authors collaboratively did this work. Initially, VJB executed the work and wrote the paper. DDB contributed to the present investigation and revised the manuscript. All the authors have reviewed and approved the content of the submitted manuscript.

\section{CONFLICT OF INTERESTS}

The authors declare no conflict of interests, financial or otherwise.

\section{FUNDING}

There is no funding to report.

\section{ETHICAL APPROVALS}

Not applicable.

\section{REFERENCES}

1. Mead FW, Fasulo TR. Scentless plant bugs, Jadera Sp. (Insecta: Hemiptera: Rhopalidae). EDIS 2002;9:1-4. doi:10.32473/edisin287-2000

2. Henry TJ. Biodiversity of Heteroptera. In: Foottit R, Adler P (eds.). Insect biodiversity: science and society. Blackwell, Chichester, UK, 2009.

3. Aldrich JR, Carroll SP, Oliver JE, Lusby WR, Rudmann AA, Waters RM. Exocrine secretions of scentless plant bugs; Jadera, Boisea, Niesthrea species (Hemiptera: Heteroptera: Rhopalidae). Biochem Syst Ecol 1990a; 18:369-76.

4. Gupta R, Singh D. Taxonomic notes on five species of the genus Cletus Stal (Heteroptera: Coreidae) from northern India with particular reference to their female genitalia ISSN 2320-7078. J Entomol Zool Studies 2013;1(6):44-51.

5. Schaefer CW, Chopra NP. Cladistic analysis of the Rhopalidae, with a list of food plants. Ann Entomol Soc Am 1982;75:224-33.

6. Paskewitz SM, McPherson JE. Life history and laboratory rearing of Arhyssus lateralis (Hemiptera: Rhopalidae) with descriptions of immature stages. Ann Entomol Soc Am 1983;76(3):477-82.

7. Wheeler AG, Henry TJ. Host plants, distribution, and description of fifth instar nymphs of two little known Heteroptera, Arhyssus hirtus (Rhopalidae) and Esperanza texana (Alydidae). Fla Entomol 1984;67:521-9.

8. Barsagade DD, Badwaik VJ. The Metamorphic changes during post embryonic development and ultrastructure of antennae in red eye bug,
Leptocoris augur (Hemiptera: Rhopalidae). Int J Res Chem Environ 2011;1(2):104-10.

9. Schaefer CW, Kotulski J. Scentless plant bugs (Rhopalidae). In: Schaefer CW, Panizzi AR (eds.). Heteroptera of economic importance. CRC Press, Boca Raton, FL, pp 309-19, 2000.

10. Badwaik VJ, Barsagade DD. Distribution of sensilla and interlocking of mouthparts in red eye bug Leptocoris augur (Hemiptera: Rhopalidae). Int J Res Biosci Agric Techn 2014;2(3):193-207.

11. Jurberg J, Rocha DS, Galvao C. Rhodnius zeledoni sp. nov.afim de Rhodnius paraensis Sherlock, Guitton\& Miles, 1977 (Hemiptera: Reduviidae: Triatominae). Biota Neotrop 2009;9(1):123-8.

12. Berenger JM, Pluot-Sigwalt D. Rhodnius amazonicus Almeida, Santos \& Sposina, 1973, bona species, close to Rhodnius pictipes Stal, 1872 (Heteroptera: Reduviidae: Triatominae). Mem Inst Oswaldo Cruz 2002;97:73-7.

13. Almeida FB, Santos EI, Sposina G. Triatomíneos da amazonia III. Acta Amazon 1973;3(2):43-66.

14. Rosa JA, Mendonca VJ, Rocha CS, Gardim S, Cilense M. Characterization of the external female genitalia of six species of Triatominae (Hemiptera: Reduviidade) by scanning electron microscopy. Mem Inst Oswaldo Cruz 2010;105:286-92.

15. Carroll SP, Loye JE, Dingle H, Mathieson M, Famula T, Zalucki M. And the beak shall inherit evolution in response to invasion. Ecol Lett 2005;8:944-51.

16. Cornelis M, Quiran E, Coscaron M. The scentless plant bug, Liorhyssus hyalinus (F.) (Hemiptera: Heteroptera: Rhopalidae) description of immature stages and notes on its life history. Zootaxa 2012;3525: 83-8.

17. Tsai JF, Hsieh YX, Redei D. The soapberry bug, Jadera haematoloma (Insecta: Hemiptera: Rhopalidae): first Asian record, with a review of bionomics. Zookeys 2013;297:1-41.

18. Badwaik VJ, Barsagade DD. Hemelytra and membranous wing morphology with respect to distribution of sensilla in soapberry bug, Leptocoris augur (Hemiptera: Rhopalidae). Glob J Multidiscip Stud 2019;8(2):99-104.

19. Gutierrez F. Valor de la genitalia comocaráctertaxonomicoen la identificacion de generos de Apiomerini (Hemiptera: Reduviidae: Harpactorinae). Bioagro 1999;11:29-39.

20. Hernandez JM. Estudiomultivariante de la genitalia masculina y femeninaen seis especies de IberodorcadionBreuning, 1943 (Coleoptera: Cerambycidae: Lamiinae) de la Comunidad de Madrid propuesta de nuevassinonimias para el grupo. Bol Asoc Esp Entomol 2000;24:97-129.

21. Castaneda-Vildozola J, Valdez-Carrasco A, EquihuaMartínez H, González-Hernández J, Romero-Nápoles J, Solís-Aguilar JF, et al. Genitalia of three species of Heilipus Germar (Coleoptera: Curculionidae). Neotrop Entomol 2007;36(6):914-8.

22. Gathalkar GB, Barsagade DD, Sen A. Oviposition and feeding behaviour of Xanthopimpla pedator (Fabricius) (Hymenoptera: Ichneumonidae) on tropical tasar silkworm, Antheraea mylitta (Drury) (Lepidoptera: Saturniidae). J Asia-Pac Entomol 2017;20:977-83.

23. Anderson P, Hallberg H. Structure and distribution of tactile and bimodal taste/tactile sensilla on the ovipositor, tarsi and antennae of the flour moth, Ephestia kuehniella (Zeller) (Lepidoptera: Pyralidae). Int J Insect Morphol Embryol 1990;19:13-23.

24. Arthur AP, Hegdekar BM, Rollins L. Component of the host haemolymph that induces oviposition in a parasitic insect. Nature 1969;223:966-7.

25. Spanhoff B, Alecke C, Kaschek N, Lange J, Meyer EI. Morphological characteristics of sensilla on the female ovipositor of Lype phaeopa (Psychomyiidae; Trichoptera). J Insect Sci 2003;3(12):1-7.

26. Richards AG, Davies RG. General textbook of entomology. 1973 In: Classification Biology. 10th edition, 2 Chapman and Hall, London, UK.

27. Acebes A, Cobb M, Feurler JF. Species-specific effects of single sensillum ablation on mating position in Drosophila. J Exp Biol 2003;206:3095-100. 
28. Seenivasagan T, Sharma KR, Shrivastava A, Parashar BD, Pant $\mathrm{SC}$, Prakash S. Surface morphology and morphometric analysis of sensilla of Asian tiger mosquito, Aedes albopictus (Skuse): an SEM investigation. J Vector Borne Dis 2009;46:125-35.

29. Matushkina NA, Klass KD. Morphology of female external genitalia in Phenes raptor (Odonata: Petaluridae). Int J Odonatol 2011;14(3):199-215.

30. Rosa da J, Mendonca VJ, Gardim S, Carvalho D. Study of the external female genitalia of 14 Rhodnius species (Hemiptera: Reduviidae: Triatominae) using scanning electron microscopy. Parasit Vectors 2014;7:7-17.

31. Gullan PJ. Male insects and galls of the genus Cylindrococcus Maskell (Homoptera: Coccoidea). J Aust Entomol Soc 1978;17:53-61.

32. Gnezdilov VM. On the systematic positions of the Bladinini kirkaldy, Tonginae kirkaldy, and Trienopinae fennah (Homoptera: Fulgoroidea). Zoosystematica Ross 2007;15(2):293-7.

33. Chlond D, Junkiert L. Peyrierocoris a new genus of Harpactorinae (Hemiptera: Heteroptera: Reduviidae) from Madagascar. Zootaxa 2010;2487:33-42.

34. Redei D, Tsai JF. A survey of the saicine assassin bugs of Taiwan (Hemiptera: Heteroptera: Reduviidae). Acta Entomologica Musei Nationalis Pragae. 2010; 50:15-32.

35. Snodgrass RE. A revised interpretation of the external reproductive organs of male insects. Smithson Miscell Coll 1957;135:1-60.

36. Matsuda R. Morphology and evolution of the insect abdomen. Pergamon Press Ltd, Oxford, UK, pp 1-534, 1976.

37. Wieczorek K, Bartosz JP. Comparative morphology of the male genitalia of Aphididae (Insecta: Hemiptera) part 1. Zoomorphology 2011;130:289-303.

38. Wieczorek K, Swiatek P. Morphology and ultrastructure of the male reproductive system of the woolly beech aphid Phyllaphis fagi (Hemiptera: Aphidoidea: Phyllaphidinae). Eur J Entomol 2008;105:707-12.

39. Redei D, Tsai JF. A survey of the saicine assassin bugs of Taiwan (Hemiptera: Heteroptera: Reduviidae). Acta Entomol Mus Nat Pragae 2010;50:15-32.
40. Polaszek A. Comparative anatomy of the male aphid reproductive system. Unpublished Ph.D. Thesis, London 1987.

41. Kozlowski MW. Mating behavior and high-level polygamy in the aphids Periphyllus cericola and Drepanosiphum platanoidis (Homoptera: Drepanosiphidae). Ethol Ecol Evol 1991;3:285-94.

42. Dagg JL, Scheurers S. Observations on some patterns of the males' sexual behavior of certain aphid species indicate the existence of the male marking pheromones. In: Nieto Nafrı'a JM, Dixon AFG (eds). Aphids in natural and managed ecosystems. Universidad de Leo'n, Leo'n, Spain, pp 167-71, 1997.

43. Dagg JL. Copula duration and sperm economy in the large thistle aphid, Uroleucon cirsii (Hemiptera: Aphididae). Eur J Entomol 2003;100:201-3.

44. Hales DF. Physiological determinants of male mating performance in aphids (Hemiptera: Aphididae). Eur J Entomol 2005;102:641-6.

45. Kaur S, Rajmohana K, Pandher S. Morphological studies on male and female genitalia of Myrmecaelurus acerbus (Walker, 1853) (Neuroptera: Myrmeleontidae). Records Zoolog Surv India 2019;119(4):438-43.

46. Lent H, Jurberg J, Galvao C. Rhodnius stal sp. n., afim de Rhodnius pictipes Stal, 1872 (Hemiptera: Reduviidae: Triatominae). Mem Inst Oswaldo Cruz 1993;88:605-14.

\section{How to cite this article:}

Badwaik VJ, Barsagade DD. Microstructure characterization of male and female external genitalia of soapberry bug, Leptocoris augur (Hemiptera: Rhopalidae). J Appl Biol Biotech 2021; 9(05):26-32. 